\title{
The glucagon-like peptide-1 receptor agonist exenatide restores impaired pro-islet amyloid polypeptide processing in cultured human islets: implications in type 2 diabetes and islet transplantation
}

\author{
Y. J. Park • Z. Ao • T. J. Kieffer $\cdot$ H. Chen $\cdot$ N. Safikhan • \\ D. M. Thompson • M. Meloche • G. L. Warnock • \\ L. Marzban
}

Received: 20 August 2012 /Accepted: 23 November 2012 /Published online: 23 December 2012

(C) Springer-Verlag Berlin Heidelberg 2012

\begin{abstract}
Aims/hypothesis Islet amyloid, formed by aggregation of human islet amyloid polypeptide (hIAPP), is associated with beta cell death in type 2 diabetes as well as in cultured and transplanted human islets. Impaired prohIAPP processing due to beta cell dysfunction is implicated in hIAPP aggregation. We examined whether the glucagon-like peptide-1 receptor (GLP-1R) agonist exenatide can restore impaired prohIAPP processing and reduce hIAPP aggregation in cultured human islets and preserve beta cell function/mass during culture conditions used in clinical islet transplantation.

Methods Isolated human islets ( $n=10$ donors) were cultured with or without exenatide in normal or elevated glucose for 2 or 7 days. Beta cell apoptosis, proliferation, mass,
\end{abstract}

Electronic supplementary material The online version of this article (doi:10.1007/s00125-012-2802-z) contains peer-reviewed but unedited supplementary material, which is available to authorised users.

Y. J. Park and Z. Ao contributed equally to these studies.

Y. J. Park $\cdot$ Z. Ao $\cdot$ H. Chen $\cdot$ N. Safikhan $\cdot$ M. Meloche $\cdot$

G. L. Warnock $\cdot$ L. Marzban $(\bowtie)$

Department of Surgery, Faculty of Medicine,

University of British Columbia, Jim Pattison Pavilion, Vancouver

General Hospital, 910 W 10th Avenue,

Vancouver, BC V5Z 4E3, Canada

e-mail: lucy.marzban@ubc.ca

T. J. Kieffer

Department of Cellular and Physiological Sciences,

Faculty of Medicine, Life Sciences Institute,

University of British Columbia, Vancouver, BC, Canada

D. M. Thompson

Department of Medicine, Faculty of Medicine,

University of British Columbia, Vancouver, BC, Canada function, cJUN N-terminal kinase (JNK) and protein kinase $\mathrm{B}$ (PKB) activation and amyloid formation were assessed. ProhIAPP, its intermediates and mature hIAPP were detected. Results Exenatide-treated islets had markedly lower JNK and caspase- 3 activation and beta cell apoptosis, resulting in higher beta/alpha cell ratio and beta cell area than nontreated cultured islets. Exenatide improved beta cell function, manifested as higher insulin response to glucose and insulin content, compared with non-treated cultured islets. Phospho-PKB immunoreactivity was detectable in exenatide-treated but not untreated cultured islets. Islet culture caused impaired prohIAPP processing with decreased mature hIAPP and increased $\mathrm{NH}_{2}$-terminally unprocessed prohIAPP levels resulting in higher release of immature hIAPP. Exenatide restored prohIAPP processing and reduced hIAPP aggregation in cultured islets.

Conclusions/interpretation Exenatide treatment enhances survival and function of cultured human islets and restores impaired prohIAPP processing in normal and elevated glucose conditions thereby reducing hIAPP aggregation. GLP$1 \mathrm{R}$ agonists may preserve beta cells in conditions associated with islet amyloid formation.

Keywords Amylin · Beta cell apoptosis · Exenatide · Glucagon-like peptide-1 · Islet amyloid polypeptide $\cdot$ Islet culture $\cdot$ Islet transplantation · ProIAPP processing · Type 2 diabetes

Abbreviations
$\begin{array}{ll}\text { GAPDH } & \text { Glyceraldehyde-3-phosphate dehydrogenase } \\ \text { GSIS } & \text { Glucose-stimulated insulin secretion } \\ \text { hIAPP } & \text { Human islet amyloid polypeptide } \\ \text { IAPP } & \text { Islet amyloid polypeptide }\end{array}$

Abbreviations

GAPDH Glyceraldehyde-3-phosphate dehydrogenase

hIAPP Human islet amyloid polypeptide

IAPP Islet amyloid polypeptide 
JNK cJUN N-terminal kinase

PC Prohormone convertase

PCNA Proliferating cell nuclear antigen

PMSF Phenylmethylsulfonyl fluoride

\section{Introduction}

Type 2 diabetes is characterised by progressive beta cell failure and reduced beta cell mass [1, 2] associated with islet amyloid formation [3-5]. Islet amyloid, mainly formed by aggregation of human islet amyloid polypeptide (hIAPP, amylin), is toxic to beta cells and contributes to progressive beta cell dysfunction and death in type 2 diabetes [3-5]. Interestingly, islet amyloid also forms in human islets during culture [6-8] and following transplantation into mouse models $[9,10]$ and patients $[11,12]$ with type 1 diabetes. The formation of amyloid in cultured human islets is associated with beta cell dysfunction and apoptosis, both of which are prevented by inhibition of hIAPP aggregation [6, 8]. Furthermore, its formation in transplanted islets leads to graft failure and recurrence of hyperglycaemia in animal models of type 1 diabetes [10, 13, 14].

Several mechanisms have been shown to mediate amyloid-induced beta cell death, including membrane disruption by hIAPP aggregates [15, 16], activation of the Fasmediated apoptosis and caspase pathways [7, 8, 17], interaction of hIAPP aggregates with components of beta cell membranes (such as heparan sulphate proteoglycans [18] or touch receptors [19]), endoplasmic reticulum stress [20, 21], oxidative stress [22], activation of the cJUN N-terminal kinase (JNK) pathway [23] and disruption of the autophagy/lysosomal pathway [24]. Growing evidence suggests that small hIAPP aggregates (e.g. oligomers) rather than large amyloid deposits induce beta cell toxicity [3, 4]. Since multiple apoptotic pathways are initiated by hIAPP aggregates, the most feasible strategy to protect beta cells from amyloid toxicity appears to be prevention of amyloid formation.

hIAPP is a normal beta cell peptide that is co-synthesised and co-secreted with insulin in response to beta cell secretagogues [25]. Three factors have been proposed to contribute to amyloid formation in type 2 diabetes: (1) presence of an amyloidogenic sequence in the hIAPP molecule [26]; (2) elevated hIAPP production and secretion from beta cells associated with an increased demand for insulin [27-29] and (3) impaired prohIAPP processing associated with beta cell dysfunction [28, 30, 31]. The mechanisms underlying amyloid formation in cultured and transplanted human islets are still unclear but lower clearance of hIAPP secreted from beta cells due to the disrupted vasculature and beta cell dysfunction caused by islet culture and transplantation may contribute to this process.
Mature IAPP is produced by cleavage of proIAPP at its $\mathrm{COOH}$ - and $\mathrm{NH}_{2}$-termini by the prohormone convertase $1 / 3$ (PC1/3) and $\mathrm{PC} 2$, respectively, the two key enzymes also responsible for processing of proinsulin [32, 33]. Cleavage by $\mathrm{PC} 1 / 3$ occurs early in the beta cell secretory pathway whereas cleavage by PC2 occurs mainly in the beta cell granules [28]. Therefore, the latter step might be impaired due to insufficient processing time in the conditions associated with release of immature granules by beta cells. The impaired processing of prohIAPP, particularly at its $\mathrm{NH}_{2}-$ terminal cleavage site, potentiates hIAPP aggregation thereby increasing amyloid-induced beta cell death [30, 31]. Thus, restoring impaired prohIAPP processing may provide a new strategy to reduce hIAPP aggregation and its beta cell toxicity in conditions associated with islet amyloid formation such as type 2 diabetes, islet culture and transplantation.

Glucagon-like peptide-1 (GLP-1) is a potent incretin hormone produced by the intestinal $\mathrm{L}$ cells in response to nutrients. GLP-1 and GLP-1 receptor (GLP-1R) agonists stimulate glucose-dependent insulin secretion, increase insulin synthesis, beta cell proliferation and neogenesis and reduce beta cell apoptosis induced by various apoptotic factors both in vitro and in vivo in animal models [34-39]. The ability of GLP-1 to enhance beta cell survival and function is of significant clinical benefit in type 2 diabetes [40, 41]. Therefore, long-acting GLP-1R agonists such as exenatide are currently used for treatment of type 2 diabetes. Moreover, clinical studies suggest that treatment of islet graft recipients with type 1 diabetes by GLP-1R agonists may improve survival and function of transplanted islets $[42,43]$.

In this study, we used human islets in culture as an ex vivo model of impaired prohIAPP processing and islet amyloid formation, to test whether exenatide could restore processing of prohIAPP thereby reducing amyloid formation and its beta cell toxicity. We also examined the protective effects of exenatide on the viability and function of beta cells in isolated human islets cultured under conditions used in clinical islet transplantation, as a potential approach to preserve beta cells during pretransplant islet culture. Finally, the effects of exenatide were tested in human islets cultured in elevated glucose to mimic the hyperglycaemic conditions of diabetes.

\section{Methods}

Materials Exenatide (Byetta) was from Amylin Pharmaceuticals (San Diego, CA, USA). Synthetic IAPP (1-37 amino acids) was from Bachem (Torrance, CA, USA). Thioflavin S, dithizone, BSA, phenylmethylsulfonyl fluoride (PMSF) and aprotinin were obtained from Sigma-Aldrich (Oakville, ON, Canada). FBS, penicillin, streptomycin and gentamicin were 
from Invitrogen (Burlington, ON, Canada). CMRL culture medium was from Mediatech (Herndon, VA, USA). All electrophoresis chemicals were from Bio-Rad Laboratories (Mississauga, ON, Canada).

IAPP antibody and antisera $\operatorname{IgG}$ purified antibody (T-4145) specific to IAPP was obtained from Peninsula Laboratories (Belmont, CA, USA). Antisera specific to $\mathrm{NH}_{2}$ - and $\mathrm{COOH}-$ terminal flanking regions of prohIAPP were provided by $\mathrm{C}$. B. Verchere (University of British Columbia, Vancouver, BC, Canada). The $\mathrm{NH}_{2}$ - and $\mathrm{COOH}$-terminal prohIAPP antisera were generated in rabbits using peptides corresponding to amino acids 4-16 (8546) and 44-56 (8548) of prohIAPP, respectively, and conjugated to keyhole limpet haemocyanin. Antibody titres were assessed by enzyme-linked immunosorbent assay (ELISA) using the synthetic peptides as standard. Antisera had no detectable cross-reactivity with mature hIAPP as assessed by western blot using synthetic hIAPP (Bachem).

Human islets Human islets isolated from male and female cadaveric pancreatic donors aged 23-61 years were provided by the Ike Barber Human Islet Transplant Laboratory (Vancouver, BC, Canada) in accordance with approved procedures and guidelines of the Clinical Research Ethics Board of the University of British Columbia. Hand-picked human islets (purity $>90 \%$ as assessed by dithizone staining) were cultured in CMRL supplemented with glucose (normal $[5.5 \mathrm{mmol} / \mathrm{l}]$ or elevated $[11.1 \mathrm{mmol} / \mathrm{l}$, to induce amyloid formation]), $10 \%$ (vol./vol.) FBS, $50 \mathrm{U} / \mathrm{ml}$ penicillin, $50 \mu \mathrm{g} / \mathrm{ml}$ streptomycin and $50 \mu \mathrm{g} / \mathrm{ml}$ gentamicin in humidified $5 \% \mathrm{CO}_{2} / 95 \%$ air at $37^{\circ} \mathrm{C}$.

Treatment of human islets with exenatide Isolated human islets were cultured free-floating in non-adherent 24-well culture plates (50 islets per well, duplicate) in 5.5 or $11.1 \mathrm{mmol} / 1$ glucose for 2 or 7 days. Exenatide (Byetta) was added to the islet culture medium in a final concentration of $10 \mathrm{nmol} / \mathrm{l}$. Culture medium and exenatide were replaced every $48 \mathrm{~h}$. To determine the optimal concentration of exenatide for these studies, human islets were cultured with exenatide (1-10 nmol/l) and beta cell apoptosis was quantified (ESM Fig. 1). The concentration of exenatide $(10 \mathrm{nmol} / \mathrm{l})$ at which islets had the lowest levels of beta-cell apoptosis was used for the following studies.

Measurement of caspase-3 activation in human islets Caspase-3 activity was measured in islet lysates from nontreated and exenatide-treated human islets (300 islets, duplicate; five human islet preparations) following 7-day culture in $5.5 \mathrm{mmol} / \mathrm{l}$ glucose using a human specific cleaved (active) caspase-3 ELISA kit from Roche Diagnostics (Laval, QC, Canada) according to the manufacturer's instructions. Data are expressed as percentage of caspase-3 activity in non-treated islets (taken as $100 \%$ ).

Immunolabelling, TUNEL and thioflavin S staining Paraffin-embedded islet sections $(5 \mu \mathrm{m})$ were dewaxed, rehydrated and blocked in $2 \%$ normal goat and/or donkey serum (Vector Laboratories, Burlingame, CA, USA). Fixed islet sections (following antigen retrieval with citrate buffer) were incubated overnight with guinea pig anti-insulin alone (1:750; Dako, Carpinteria, CA, USA) or with rabbit antiglucagon (1:750; Dako), anti-oligomer (A11; 1:400; Invitrogen), anti-cleaved caspase-3 (1:100; Cell Signaling, Pickering, ON, Canada), anti-phospho-JNK (1:100; Cell Signaling), anti-phospho-PKB (1:50; Cell Signaling) or mouse anti-PCNA (1:250; Cell Signaling). Islet sections were then incubated with Texas red-conjugated anti-guinea pig (1:750; Jackson Laboratories, West Grove, PA, USA) and Alexa 488-conjugated anti-rabbit (1:100; Molecular Probes, Eugene, OR, USA) or anti-mouse (1:250) for $1 \mathrm{~h}$ at room temperature. Islet sections immunolabelled for insulin and hIAPP oligomers were incubated with Alexa 488conjugated anti-guinea pig (1:750; Molecular Probes) and Texas red-conjugated anti-rabbit (1:400; Jackson). For double insulin and TUNEL or thioflavin S (amyloid) staining, after immunolabelling for insulin, islet sections were incubated with TUNEL reaction mixture (Roche Diagnostics) for $30 \mathrm{~min}$ at $37^{\circ} \mathrm{C}$ or $5 \mathrm{~min}$ at room temperature with $0.5 \%$ (wt/vol.) thioflavin S solution.

Assessment of islet insulin content and basal and glucosestimulated insulin release Insulin release from human islets was measured in the culture medium from exenatide-treated and non-treated islets following 2 or 7 days' culture in $11.1 \mathrm{mmol} / \mathrm{l}$ glucose. Insulin response to elevated glucose was measured in exenatide-treated and non-treated islets by performing a glucose-stimulated insulin secretion (GSIS) test following 7-day culture in $11.1 \mathrm{mmol} / \mathrm{l}$ glucose. Briefly, islets were pre-incubated $(1 \mathrm{~h})$ in $300 \mu \mathrm{KRB}$ containing $10 \mathrm{mmol} / \mathrm{l}$ HEPES (pH7.4), 0.25\% BSA and $1.67 \mathrm{mmol} / \mathrm{l}$ glucose at $37^{\circ} \mathrm{C}$ followed by $1 \mathrm{~h}$ incubation in $150 \mu \mathrm{KRB}$ containing $1.67 \mathrm{mmol} / \mathrm{l}$ (basal insulin release) and then $1 \mathrm{~h}$ incubation in KRB with $16.7 \mathrm{mmol} / \mathrm{l}$ glucose (stimulated insulin release). Islets were lysed in $100 \mu \mathrm{l}$ of $1 \mathrm{~mol} / \mathrm{l}$ acetic acid $/ 0.1 \%$ BSA lysis buffer followed by $10 \mathrm{~min}$ incubation at $100^{\circ} \mathrm{C}$. Incubation media and islet lysates were centrifuged and supernatant fractions were frozen $\left(-70^{\circ} \mathrm{C}\right)$ until assayed using a human specific insulin ELISA kit (ALPCO Diagnostics, Salem, NH, USA).

Immunoprecipitation, electrophoresis and immunoblotting About 100 islets were lysed in $30 \mu$ lysis buffer containing $50 \mathrm{mmol} / \mathrm{l}$ Tris- $\mathrm{HCl}(\mathrm{pH} 8.0), 150 \mathrm{mmol} /$ $1 \mathrm{NaCl}, 0.02 \%$ sodium azide, $0.1 \%$ sodium dodecyl 


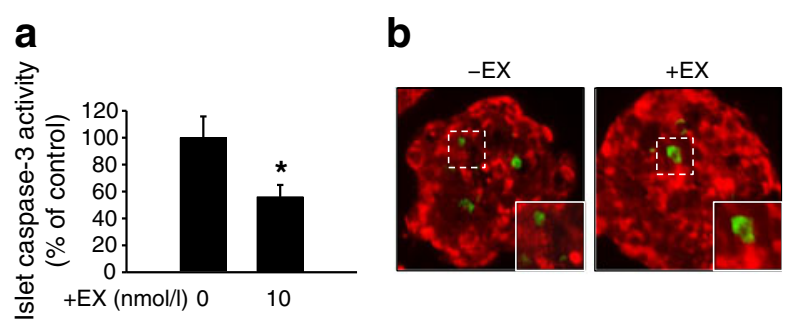

C
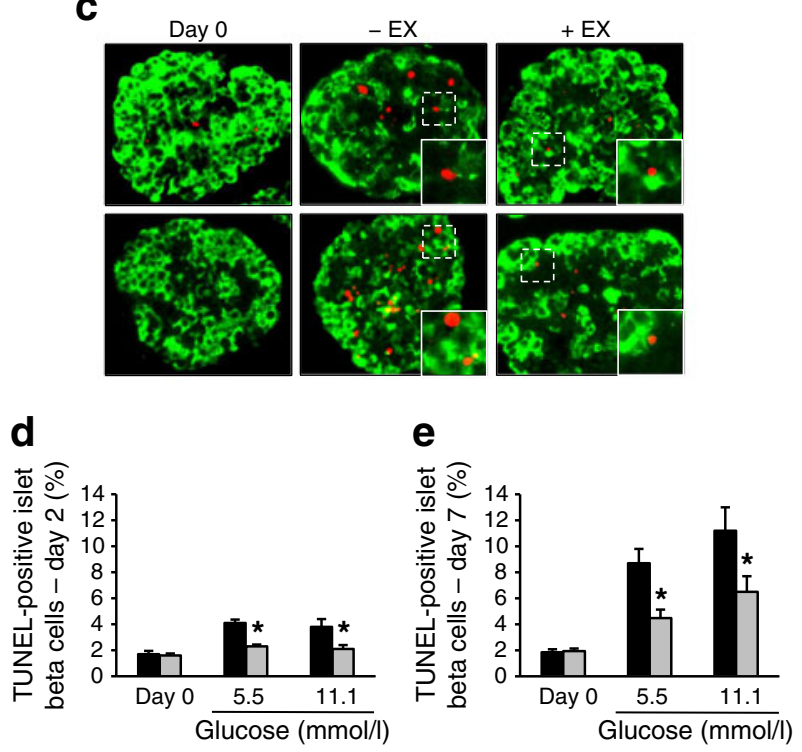

\section{f}
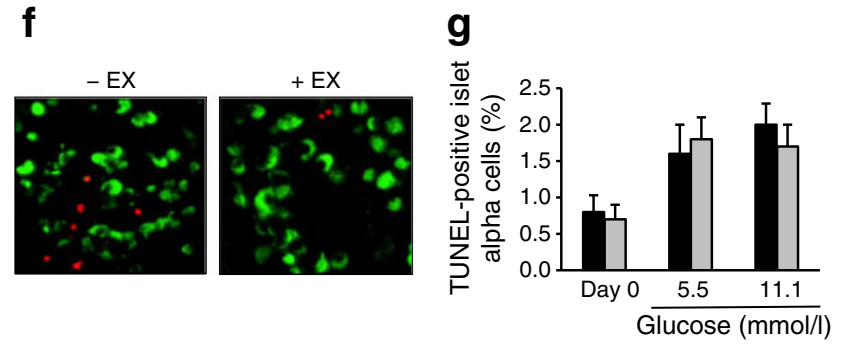

sulphate, 1\% Nonidet P-40, 0.5\% sodium deoxycholate, $1 \mathrm{mmol} / 1 \mathrm{PMSF}$ and $10 \mu \mathrm{g} / \mathrm{ml}$ aprotinin, for $25 \mathrm{~min}$ on ice and vortexed every $5 \mathrm{~min}$. Samples were centrifuged $\left(15,000 \mathrm{~g}, 10 \mathrm{~min}, 4^{\circ} \mathrm{C}\right)$ and the supernatant fractions were frozen at $-70^{\circ} \mathrm{C}$ until analysis. To detect the (pro)IAPP immunoreactive forms released from islets, culture medium was incubated with IAPP antibody (T-4145) for $6 \mathrm{~h}$ at $4^{\circ} \mathrm{C}$ followed by $2.5 \mathrm{~h}$ incubation with protein $\mathrm{G}$ sepharose (Amersham, Baie D'Urfe, QC, Canada). Aliquots of protein (10 or $15 \mu \mathrm{g}$ ) from islet lysates or protein G-(pro)IAPP complex in $4 \%$ sample buffer were electrophoresed on polyacrylamide gel (using Tris-tricine buffer for IAPP) followed by immunoblot with $\mathrm{NH}_{2}$-terminal (8546) or $\mathrm{COOH}$ terminal (8548) prohIAPP specific antisera at 1:100, glyceraldehyde-3-phosphate dehydrogenase (GAPDH) or IAPP (T-4145) antibodies at 1:1,000, for $1 \mathrm{~h}$ at room temperature. For detection of phosphorylated JNK, membranes were incubated with phospho-JNK antibody (1:750; Cell
Fig. 1 Treatment with the GLP-1R agonist exenatide reduces beta cell apoptosis in human islets during culture. Human islets were cultured in CMRL containing 5.5 or $11.1 \mathrm{mmol} / 1$ glucose with (+EX) or without (-EX) exenatide $(10 \mathrm{nmol} / \mathrm{l})$ for 2 or 7 days. (a) The cellular level of active (cleaved) caspase-3 was measured in the lysates from 7-day cultured exenatide-treated and non-treated islets using a human specific cleaved caspase-3 ELISA kit as detailed in Methods. (b) Paraffinembedded sections from 7-day cultured exenatide-treated and nontreated islets were immunolabelled for insulin (red) and cleaved caspase-3 (green). (c) Immunolabelling of islet sections for insulin (green) and TUNEL (red) after 7-day culture in $5.5 \mathrm{mmol} / \mathrm{l}$ (upper panel) or $11.1 \mathrm{mmol} / \mathrm{l}$ glucose (lower panel) with or without exenatide. $(\mathbf{d}, \mathbf{e})$ The proportion of apoptotic beta cells was quantified pre-culture and following 2 or 7 days' culture in each condition. (f) The apoptotic alpha cells were detected following 7-day culture with or without exenatide by immunolabelling for glucagon (green) and TUNEL (red); and (g) the proportion of apoptotic alpha cells was quantified in each condition. Black bars, non-treated; grey bars, exenatide treated. The white squares denote regions enlarged in each image. The caspase3 activity is expressed as a percentage of non-treated islets taken as $100 \%$. The proportion of apoptotic beta (or alpha) cells was calculated by manual counting of double insulin (or glucagon) and TUNELpositive cells in each islet in a total of 50 islets per condition for each human islet preparation. Results are expressed as means \pm SEM of ten independent studies from ten human islet preparations (five for caspase-3 and alpha cell studies) performed in duplicate. ${ }^{*} p<0.05$ by Student's $t$ test or two-way ANOVA vs corresponding non-treated group

Signaling) overnight at $4^{\circ} \mathrm{C}$. Membranes were then washed and incubated with horseradish peroxidase-conjugated anti-rabbit IgG or anti-mouse $\mathrm{IgG}$ for GAPDH (Amersham) at 1:5,000 for $1 \mathrm{~h}$. Immunodetection was performed using an enhanced chemiluminescence detection kit (Amersham). Protein bands on the films were analysed by densitometry using Image Lab software (Bio-Rad).

Statistical analysis Data are expressed as means \pm SEM. Statistical analyses were performed using one-way or twoway ANOVA followed by Newman-Keuls test or by Student's $t$ test as appropriate. A $p$ value of $<0.05$ was considered significant. The studies were performed on ten human islet preparations in duplicate unless otherwise stated in the figure legends.

\section{Results}

Treatment with the GLP-1R agonist exenatide reduces caspase3 activation and beta cell apoptosis in cultured human islets Islet beta cell apoptosis was assessed by activation of caspase-3 and quantitative immunolabelling for insulin and TUNEL. Exenatide-treated human islets had significantly lower caspase-3 activation than non-treated cultured islets (Fig. 1a, b). Furthermore, treatment with exenatide markedly reduced the number of TUNEL-positive (apoptotic) beta cells in human islets cultured for 2 or 7 days in normal or elevated glucose conditions (Fig. 1c-e). The anti-apoptotic effects of exenatide were concentration dependent with a maximal 
effect observed at $10 \mathrm{nmol} / 1$ (ESM Fig. 1). Despite the high rate of beta cell apoptosis, cultured human islets had a very low number of apoptotic alpha cells with no difference detectable between exenatide-treated and non-treated islets (Fig. 1f, g).

Reduced beta cell apoptosis in exenatide-treated human islets during culture is associated with higher islet beta/ alpha cell ratio and beta cell area We tested whether reduced beta cell apoptosis is associated with higher beta cell mass in exenatide-treated human islets as compared with non-treated cultured islets. Islets were immunolabelled for insulin and glucagon following culture in normal or elevated glucose with or without $10 \mathrm{nmol} / \mathrm{l}$ exenatide (Fig. 2a). There was no detectable difference in islet beta/alpha cell ratio or islet beta cell area between 2-day cultured exenatide-treated and non-treated islets (Fig. 2b, c). The progressive beta cell death in human islets during 7-day culture decreased beta cell mass manifested as reduced islet beta/alpha cell ratio and beta cell area as compared with pre-culture islets (Fig. 2d, e). Treatment with exenatide markedly increased islet beta/alpha cell ratio and preserved islet beta cell area during 7-day culture.

Treatment with exenatide is associated with enhanced beta cell proliferation and increased protein kinase $B$ activation in cultured human islets To assess the potential effects of exenatide on beta cell proliferation, exenatide-treated and non-treated islets were immunolabelled for insulin and proliferating cell nuclear antigen (PCNA, a marker of cell proliferation) or phospho(active)-protein kinase $\mathrm{B}$ (PKB). The beta cell proliferation rate was comparable in 2-day cultured exenatide-treated and non-treated islets but was higher in exenatide-treated islets at 5.5 and $11.1 \mathrm{mmol} / \mathrm{l} \mathrm{glu}-$ cose following 7-day culture, suggesting that treatment with exenatide may enhance beta cell proliferation in cultured human islets (Fig. 3a, b). We further detected phospho-PKB in exenatide-treated islets as a potential mechanism mediating the beta cell protective effects of exenatide. PhosphoPKB-positive beta cells were detectable by immunolabelling in human islets cultured in elevated glucose but not normal glucose conditions. Interestingly, phospho-PKB-positive beta cells were detected in exenatide-treated human islets at both 5.5 and $11.1 \mathrm{mmol} / \mathrm{l}$ glucose (Fig. $3 \mathrm{c}$ ), suggesting that PKB may play a role in mediating the protective effects of exenatide on beta cell survival during islet culture.

Treatment with exenatide markedly enhances beta cell function in cultured human islets Islet insulin content and insulin release from the exenatide-treated and non-treated human islets were measured to test if enhanced beta cell survival during islet culture with exenatide is associated with improved beta cell function. Exenatide-treated islets had a

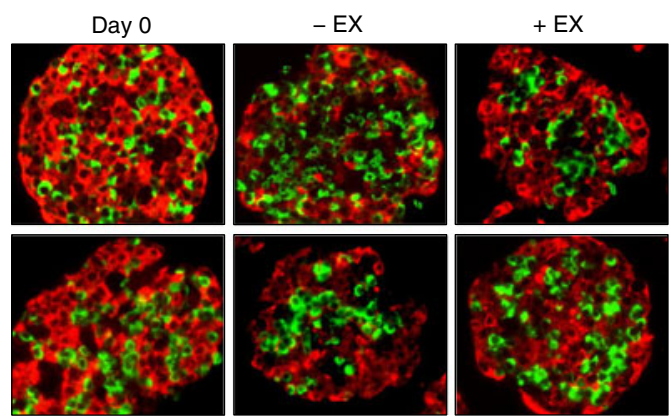

b

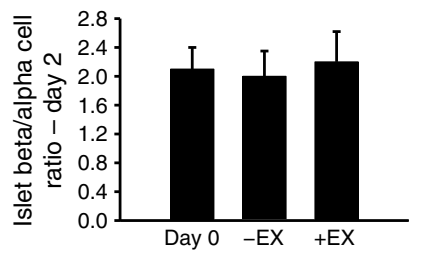

C
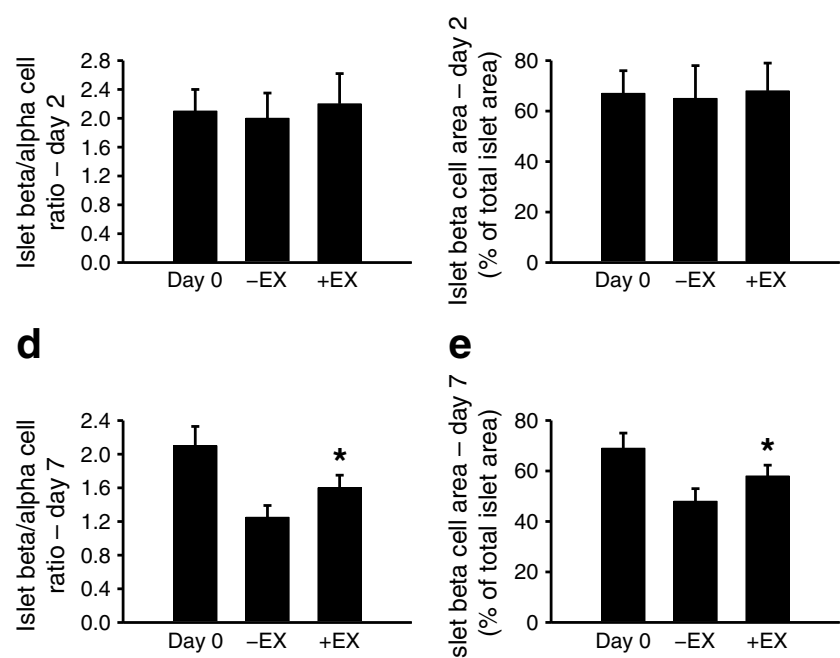

e

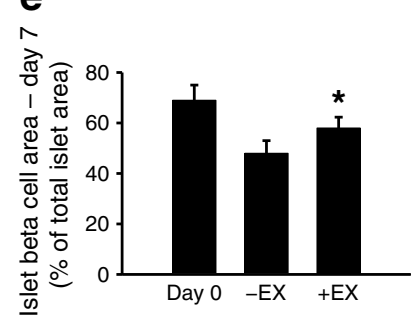

Fig. 2 Reduced beta cell apoptosis in exenatide-treated human islets is associated with increased islet beta/alpha cell ratio and beta cell area/ total islet area during culture. (a) Paraffin-embedded sections from freshly isolated or 7-day cultured human islets in 5.5 (upper panel) or $11.1 \mathrm{mmol} / 1$ glucose (lower panel) with $(+\mathrm{EX})$ or without $(-\mathrm{EX})$ exenatide $(10 \mathrm{nmol} / \mathrm{l})$ were double immunolabelled for insulin (red) and glucagon (green). Quantification of islet beta/alpha cell ratio and beta cell area/total islet area after 2 days' $(\mathbf{b}, \mathbf{c})$ or 7 days' $(\mathbf{d}, \mathbf{e})$ culture with or without exenatide. Data are expressed as the ratio of insulin/ glucagon-positive islet cells and insulin-positive islet area/total islet area, respectively, in each islet in a total of about 50 islets per condition. Results are expressed as means \pm SEM of ten independent studies (ten human islet preparations) performed in duplicate. ${ }^{*} p<0.05$ by oneway ANOVA vs corresponding non-treated group

higher insulin release during culture in $11.1 \mathrm{mmol} / \mathrm{l}$ glucose than non-treated islets, which was more profound on day 2 of culture than day 7 (Fig. 4a, c). Islet insulin content was not significantly different in 2-day cultured exenatidetreated and non-treated islets but was higher in 7-day exenatide-treated islets (Fig. 4b, d). Moreover, there was no detectable difference in basal insulin release (1.67 mmol/1 glucose) between exenatide-treated and nontreated islets cultured in $11.1 \mathrm{mmol} / \mathrm{l}$ glucose for 7 days but exenatide-treated islets had a greater insulin response to elevated glucose (Fig. 4e) associated with their higher insulin content (Fig. 4f). 

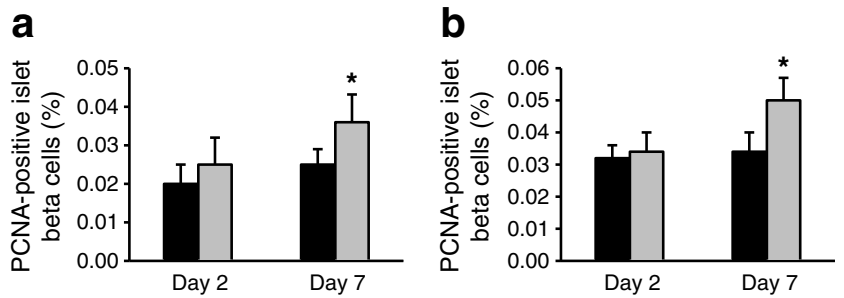

C

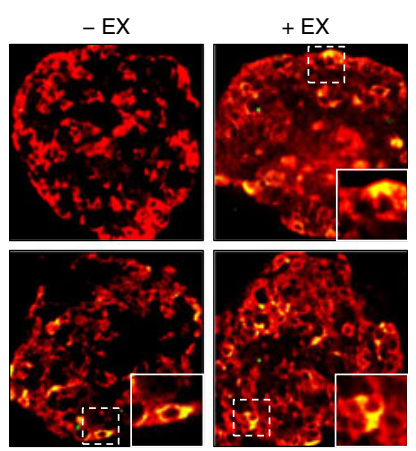

Fig. 3 Islet beta cell proliferation and PKB activation in the exenatidetreated and non-treated cultured human islets. The proportion of PCNA-positive (proliferative) beta cells was assessed by quantitative insulin and PCNA immunolabelling of paraffin-embedded sections from exenatide-treated $(+\mathrm{EX})$ and non-treated $(-\mathrm{EX})$ human islets following 2 or 7 days' culture in $5.5 \mathrm{mmol} / \mathrm{l}$ (a) or $11.1 \mathrm{mmol} / 1$ glucose (b). Black bars, non-treated; grey bars, exenatide treated. (c) Double immunolabelling of human islet sections for insulin (red) and phospho (active)-PKB (green) following 7-day culture in $5.5 \mathrm{mmol} / \mathrm{l}$ (upper panels) or $11.1 \mathrm{mmol} / 1$ glucose (lower panels) with or without exenatide $(10 \mathrm{nmol} / \mathrm{l})$. The white squares denote regions enlarged in each image. The proportion of PCNA-positive beta cells was quantified by manual counting of double PCNA- and insulin-positive cells and total number of insulin-positive cells in each islet in about 50 islets per condition. Results are expressed as means \pm SEM of eight independent studies (eight human islet preparations) performed in duplicate. ${ }^{*} p<0.05$ by two-way ANOVA vs corresponding non-treated group

Improved beta cell function with exenatide treatment restores impaired processing of prohIAPP in human islets during culture (Pro)hIAPP immunoreactive forms, including prohIAPP, its intermediates and mature hIAPP (Fig. 5a), were identified in the exenatide-treated and non-treated islet lysates following 7-day culture in normal or elevated glucose. Mature hIAPP was the major (pro)hIAPP immunoreactive form detected in freshly isolated human islets with low levels of unprocessed and partially processed prohIAPP also detectable (Fig. 5b). Islet culture resulted in impaired prohIAPP processing manifested as elevated levels of partially processed prohIAPP form(s) at normal and high glucose conditions (Fig. 5b, c), suggesting that both islet culture and elevated glucose can induce impaired prohIAPP processing in human islets. The antisera against the $\mathrm{NH}_{2}$ terminus of prohIAPP identified this elevated intermediate form to be the $\mathrm{NH}_{2}$-terminally unprocessed prohIAPP (Fig. 5d). The level of $\mathrm{COOH}$-terminal unprocessed prohIAPP intermediate remained unchanged during 7-day culture
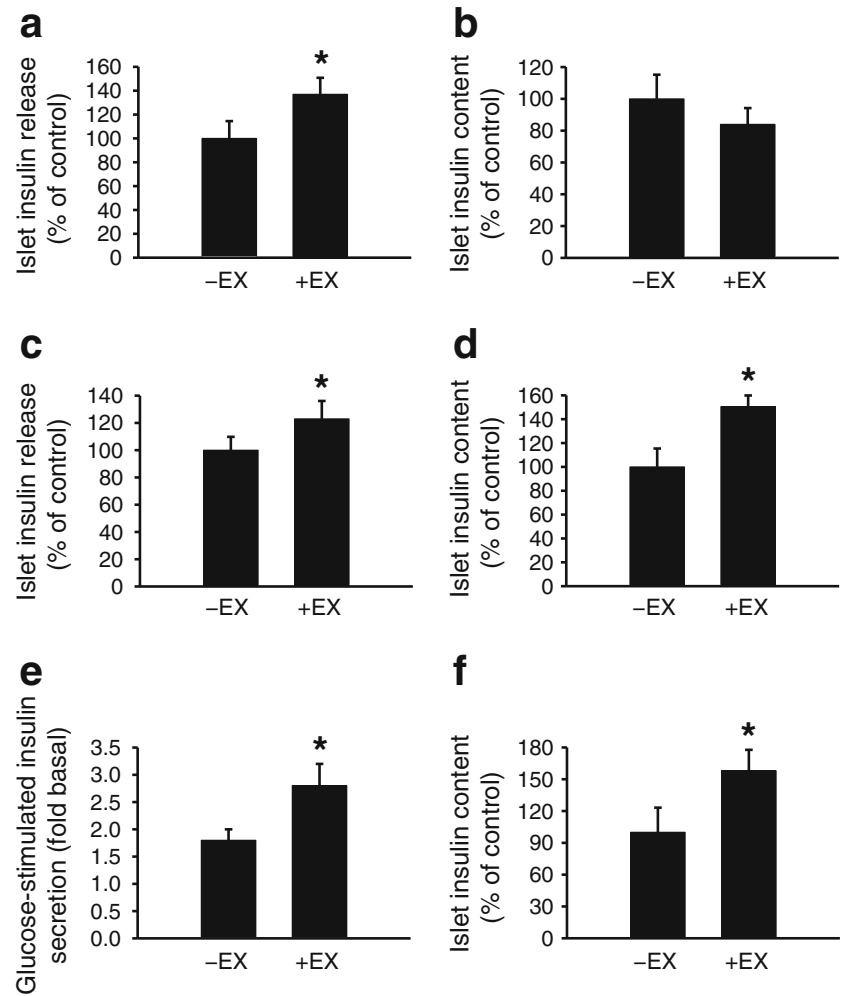

Fig. 4 The exenatide-treated human islets have higher insulin content and insulin response to elevated glucose than non-treated cultured islets. Insulin release and islet insulin content were measured in the culture medium and islet lysates following 2 days (a, b) or 7 days $(\mathbf{c}, \mathbf{d})$ culture in $11.1 \mathrm{mmol} / 1$ glucose with $(+\mathrm{EX})$ or without $(-\mathrm{EX})$ exenatide (10 nmol/1). (e) Islet insulin response to glucose stimulation (16.7 mmol/1) and (f) islet insulin content in 7-day cultured (11.1 mmol/1 glucose) exenatide-treated and non-treated human islets were measured following incubation in exenatide-free medium by performing a glucose-stimulated insulin release test as detailed in Methods. Islet insulin release and insulin content are expressed as percentage of non-treated islets taken as $100 \%$. Glucose stimulated insulin release is reported as fold increase over basal insulin release (1.67 mmol/1 glucose). Results are expressed as means \pm SEM of ten independent studies (ten human islet preparations) performed in duplicate. ${ }^{*} p<0.05$ by Student's $t$ test vs corresponding non-treated group

(Fig. 5d), suggesting that impaired prohIAPP processing occurred mainly at its $\mathrm{NH}_{2}$-terminal cleavage site. ProhIAPP intermediate(s) was the major form released from the nontreated cultured islets along with low levels of mature hIAPP (Fig. 5b).

Enhanced beta cell function with exenatide treatment restored impaired prohIAPP processing and markedly reduced $\mathrm{NH}_{2}$-terminally unprocessed prohIAPP levels in human islets during culture with normal and elevated glucose (Fig. 5b, c). ProhIAPP protein levels were comparable in exenatide-treated and non-treated islets. Also, exenatide treatment did not have any significant effect on IAPP mRNA levels (data not shown). Finally, improved prohIAPP processing in exenatide-treated islets was associated with reduced release of prohIAPP intermediate forms. Thus, mature hIAPP 
was the main (pro)hIAPP form released from exenatidetreated islets (Fig. 5b).

Enhanced prohIAPP processing in exenatide-treated human islets is associated with reduced amyloid formation during culture Impaired prohIAPP processing at its $\mathrm{NH}_{2}$-terminus has been shown to contribute to amyloid formation [30, 31]. Therefore, we examined whether improved prohIAPP processing in exenatide-treated human islets can decrease formation of hIAPP aggregates, thereby reducing amyloid beta cell toxicity. hIAPP oligomers and thioflavin S (amyloid)positive islets were absent in freshly isolated human islets but

a

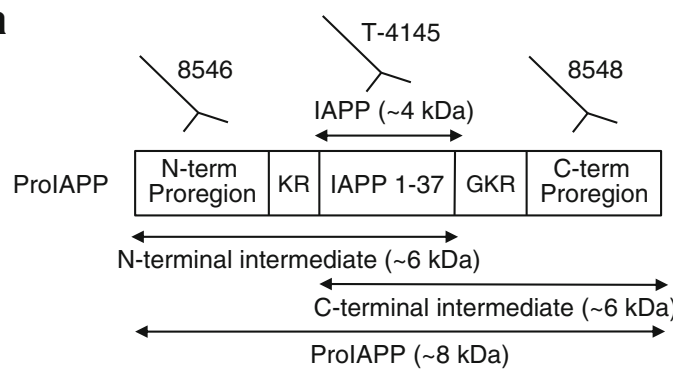

b

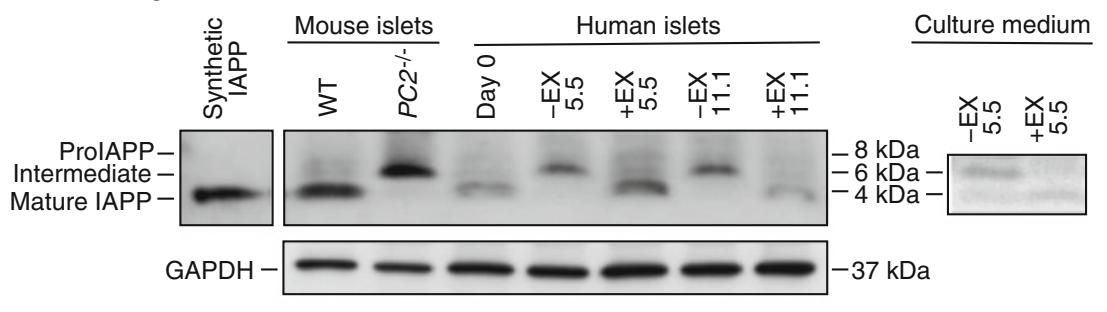

C

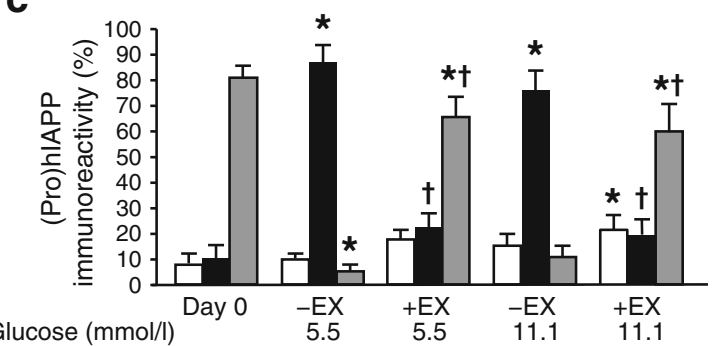

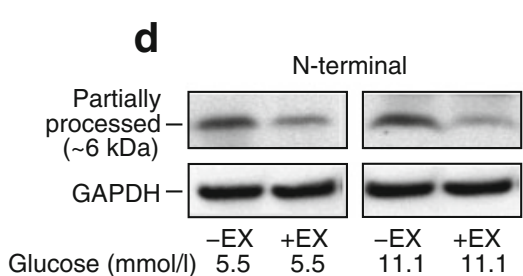

Fig. 5 Improved beta cell function by treatment with exenatide restores impaired processing of prohIAPP in human islets during culture. (a) Schematic diagram demonstrating the antigen binding sites for each (pro)IAPP antibody. IgG purified anti-IAPP (T-4145) recognises all immunoreactive forms of (pro)IAPP. $\mathrm{NH}_{2}$-terminal (term) antiserum recognises prohIAPP and its $\mathrm{NH}_{2}$-terminally unprocessed intermediate form. COOH-terminal antiserum recognises prohIAPP and its $\mathrm{COOH}$-terminally unprocessed intermediate form. (b) The cellular protein levels of prohIAPP, its intermediates and mature form were detected in the exenatide-treated $(+\mathrm{EX})$ and non-treated $(-\mathrm{EX})$ human islets following 7-day culture in 5.5 or $11.1 \mathrm{mmol} / 1$ glucose by western blot in islet lysates (left) or culture medium (right) followed by immunoblot using an antibody that recognises both mature and immature forms of IAPP. Islet lysates from wild-type mice that mainly contain mature IAPP and Pc2 (also known as Pcsk2) knockout mice

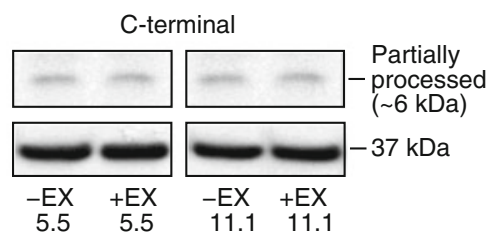

that contain high levels of $\mathrm{NH}_{2}$-terminal unprocessed proIAPP and lack mature IAPP (due to blocked proIAPP processing at its $\mathrm{NH}_{2}$-terminus) are shown for comparison. (c) Densitometric analyses of immunoblots are presented as the percentage of each (pro)hIAPP-immunoreactive molecular form with total (pro)hIAPP immunoreactivity taken as $100 \%$. White bars, prohIAPP; black bars, hIAPP intermediates; grey bars, mature hIAPP. (d) ProhIAPP and its $\mathrm{NH}_{2}$ - and $\mathrm{COOH}$-terminal prohIAPP intermediate forms were detected in the exenatide-treated and non-treated human islet lysates using antisera specific to the $\mathrm{NH}_{2}$ - and $\mathrm{COOH}-$ terminal prohIAPP, respectively. The immunoblots are representative of five independent experiments (five human islet preparations). Densitometric analyses data are expressed as means \pm SEM. $* p<0.05$ by two-way ANOVA vs corresponding molecular form in freshly isolated islets (day 0 ); ${ }^{\dagger} p<0.05$ by two-way ANOVA vs corresponding molecular form in non-treated cultured islets 
were present in 7-day cultured islets (Fig. 6a, b). Interestingly, the number of islets containing hIAPP oligomers was markedly lower in human islets treated with exenatide than nontreated cultured islets as assessed by immunolabelling for insulin and hIAPP oligomers (Fig. 6c). Furthermore, eight of ten exenatide-treated human islet preparations had lower number of thioflavin S-positive islets and islet amyloid area than non-treated cultured islets and two had comparable levels of amyloid formation (Fig. 6d, e).

Exenatide treatment reduces JNK activation induced by endogenously formed hIAPP aggregates in human islets during culture We tested whether amyloid formation in cultured human islets induces JNK activation and examined the effects of exenatide on JNK activation as a potential mechanism by which exenatide may protect beta cells from amyloid toxicity. Immunolabelling for insulin and phosphoJNK revealed that amyloid formation in cultured human islets was associated with an increased number of
phospho-JNK-positive beta cells and that exenatide-treated islets had a markedly lower number of phospho-JNKpositive beta cells than non-treated cultured islets (Fig. 7a). There was no significant difference between phospho-JNK protein levels in whole lysates from exenatide-treated and non-treated human islets as revealed by western blot (Fig. 7b), likely because in whole-islet lysates, alpha cells that form a significant proportion of cells in human islets mask the changes in beta cell phospho-JNK levels induced by hIAPP aggregates.

\section{Discussion}

In this study, we used human islets in culture as an ex vivo model of endogenous islet amyloid formation and impaired beta cell function. Our results demonstrated that exenatide, a GLP-1R agonist, enhances beta cell survival and function during culture conditions used in clinical islet transplantation

\section{a}

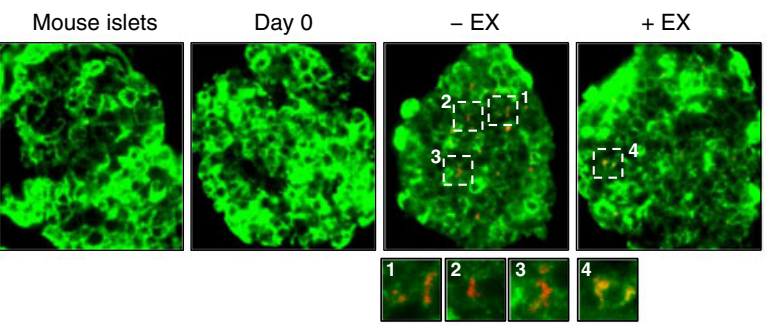

b

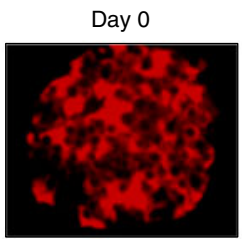

Day 7

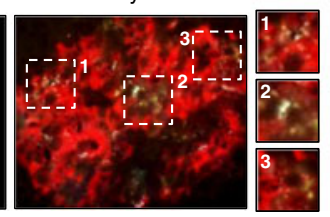

C

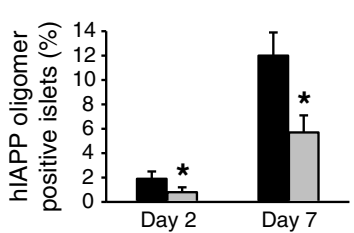

d

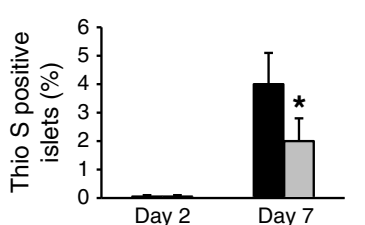

e

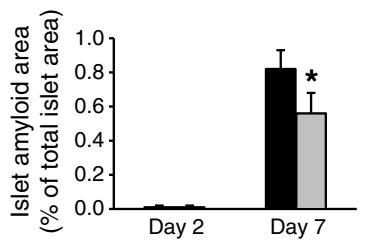

Fig. 6 Enhanced prohIAPP processing in exenatide-treated human islets is associated with reduced islet amyloid formation during culture. (a) Formation of hIAPP oligomers was detected in freshly isolated and 7-day cultured human islets in $11.1 \mathrm{mmol} / 1$ glucose with $(+\mathrm{EX})$ or without (-EX) exenatide $10 \mathrm{nmol} / 1$ by immunolabelling for insulin (green) and hIAPP oligomers (A11 antibody; red). Paraffin-embedded sections from 7-day cultured wild-type mouse islets that do not express hIAPP were used as control. (b) Amyloid deposition was detected in freshly isolated and 7-day cultured human islets by immunolabelling for insulin (red) and thioflavin S (amyloid) staining (grey). The white squares denote regions enlarged in each image. The proportion of hIAPP oligomer-positive (c) or thioflavin S (amyloid)-positive human islets (d) to total number of islets in each condition and (e) islet amyloid area/total islet area are shown. Black bars, non-treated; grey bars, exenatide-treated. The proportion of hIAPP oligomer-positive and amyloid-positive islets are expressed as the ratio of islets containing hIAPP oligomers or amyloid deposits to total number of islets in each condition in a total of about 50 islets. Islet amyloid area is reported as the percentage of thioflavin S-positive area to total islet area in each islet in a total of about 50 islets per condition. Results are expressed as means \pm SEM of ten independent studies from ten human islet preparations (four for hIAPP oligomer studies). ${ }^{*} p<0.05$ by Student's $t$ test vs corresponding non-treated group 
a
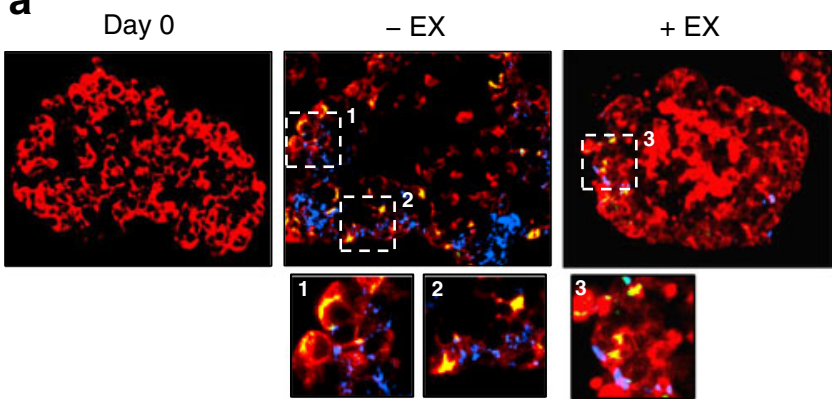

b

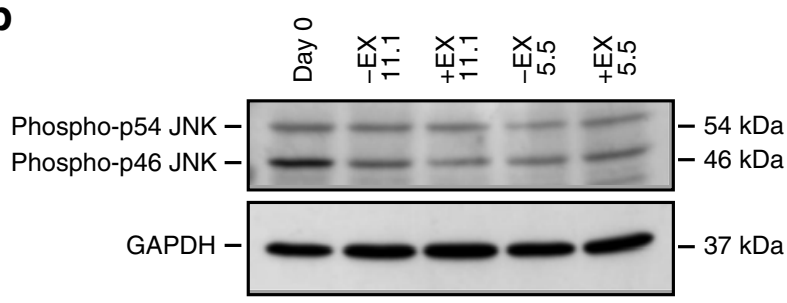

Fig. 7 Exenatide treatment reduces amyloid-induced JNK activation in human islets during culture. (a) Double immunolabelling of paraffin-embedded human islet sections for insulin (red) and phospho (active)-JNK (green) with thioflavin S staining (blue) following 7 days' culture in $11.1 \mathrm{mmol} / 1$ glucose with $(+\mathrm{EX})$ or without $(-\mathrm{EX})$ exenatide $(10 \mathrm{nmol} / \mathrm{l})$. The white squares denote regions enlarged in each image. (b) The cellular content of phospho-JNK was detected by western blot in lysates from freshly isolated or 7-day cultured human islets in 5.5 or $11.1 \mathrm{mmol} / \mathrm{l}$ glucose followed by immunoblot using an antibody that recognises phosphorylated forms of JNK. Images represent four independent studies (four human islet preparations)

thus providing a feasible approach to preserve beta cells during pre-transplant islet culture. We further showed that enhanced beta cell function with exenatide treatment can restore impaired prohIAPP processing in cultured human islets resulting in lower release of immature (pro)hIAPP forms from beta cells and thereby reducing hIAPP aggregation.

Treatment with exenatide markedly lowered beta cell apoptosis in human islets during 2 and 7 days' culture at both normal and elevated glucose conditions. This resulted in a higher islet beta/alpha cell ratio and beta cell/total islet area in 7-day exenatide-treated islets than non-treated cultured islets, suggesting that exenatide treatment preserves beta cell mass during islet culture. These findings are consistent with those of a previous study, which showed that GLP-1 reduces cell apoptosis in cultured human islets [34]. Furthermore, the rate of apoptosis was much lower in alpha cells than beta cells during culture and treatment with exenatide had no detectable effect on alpha cell survival. The beta cell proliferation rate was higher in 7-day exenatidetreated islets than non-treated cultured islets, suggesting that exenatide treatment may enhance beta cell proliferation during islet culture. However, considering the low beta cell proliferation rate in human islets during culture, changes in beta cell proliferation does not appear to play a significant role in the preservation of beta cell mass by exenatide during islet culture.

Previous studies have suggested that GLP-1 protects beta cells from apoptosis in a PKB-dependent manner in transformed beta cells $[35,38,44]$. Thus, we detected phospho (active)-PKB immunoreactivity in exenatide-treated and non-treated human islets. Phospho-PKB positive beta cells were not detectable by immunostaining in islet beta cells cultured in normal glucose but were detectable in a portion of beta cells cultured in high glucose. Interestingly, phosphoPKB-positive beta cells were present in exenatide-treated islets regardless of glucose concentration, suggesting that exenatide treatment increases PKB phosphorylation independent of elevated glucose conditions. Thus, PKB signalling may play a role in mediating the beta cell protective effects of exenatide during islet culture and amyloid formation.

The exenatide-treated human islets had a higher insulin secretion than non-treated islets cultured in $11.1 \mathrm{mmol} / 1$ glucose but the effects of exenatide on islet insulin release was more profound on day 2 than day 7 . One possible explanation for the decrease in exenatide-induced insulin release during 7-day culture with elevated glucose is downregulation of the GLP-1 receptors on beta cells [45]. Furthermore, 7-day exenatide-treated islets had comparable basal insulin release but a greater insulin response to elevated glucose following incubation in exenatide-free buffer and had a higher insulin content. Therefore, it appears that the effects of exenatide on beta cells are maintained after its removal. In support, a previous study has reported that treatment with GLP-1 increases beta cell insulin content in human isolated islets [34].

One of the key findings of this study is to show that exenatide treatment restores impaired prohIAPP processing in human islets. Islet culture was associated with impaired prohIAPP processing manifested as elevated cellular content of $\mathrm{NH}_{2}$-terminally unprocessed prohIAPP and its higher release from beta cells. Exenatide treatment markedly enhanced prohIAPP processing resulting in lower cellular levels of $\mathrm{NH}_{2}$-terminally unprocessed prohIAPP and higher levels of mature hIAPP. The effects of exenatide on prohIAPP appear to be mainly on its processing rather than its expression since only a modest increase in prohIAPP protein levels and no detectable changes in IAPP mRNA levels were observed in exenatide-treated islets. Furthermore, exenatide treatment reduced the proportion of immature (pro)hIAPP to hIAPP released from human islets during culture. Thus, the major immunoreactive form released from exenatide-treated islets was mature hIAPP. Accordingly, treatment with exenatide was shown to reduce serum proinsulin-to-insulin ratio in type 1 diabetes recipients of human islets with graft dysfunction [43].

Increased insulin secretion from beta cells by GLP-1R agonists also increases the release of hIAPP that is co- 
secreted with insulin $[25,29]$, raising the possibility that GLP-1R agonists may potentiate amyloid formation in human islets. However, our studies suggest that exenatidetreated human islets release mainly mature hIAPP rather than immature (pro)hIAPP. Accordingly, previous studies have shown that an elevated hIAPP level per se, such as its overexpression in $\mathrm{h} I A P P$-expressing mice, is not sufficient for amyloid formation [46] whereas elevated production and release of immature (pro)hIAPP potentiates hIAPP aggregation $[30,31]$.

Importantly, improved prohIAPP processing by enhancing beta cell function in human islets with exenatide was associated with a lower number of islets containing hIAPP oligomers and amyloid deposits as well as a lower islet amyloid area in relation to total islet area compared with non-treated cultured islets. These findings suggest that enhancing beta cell function at early stages of islet culture may have a significant impact on reducing amyloid formation. Similarly, treatment of patients with type 2 diabetes and islet recipients with type 1 diabetes, at early stages of beta cell dysfunction may slow down the process of hIAPP aggregation and thereby amyloid-induced beta cell death. In support, two recent studies have demonstrated that treatment with GLP-1R agonists, such as exenatide and liraglutide, reduces $A \beta$ oligomers, amyloid plaque formation and toxicity in the brains of mice in models of Alzheimer's disease $[47,48]$.

Treatment with exendin-4 in $\mathrm{h} I A P P$-expressing transgenic mouse islets, which form amyloid much faster than human islets during culture, was shown to potentiate amyloid formation during short-term (2 day) culture with high glucose [29]. This finding suggests that the level of hIAPP released from islets (human vs transgenic mouse) and the glucose conditions to which islets are exposed may play important roles in the net effect of GLP-1R agonists on amyloid formation. Interestingly, exendin-4 treated hIAPPexpressing mouse islets, despite their higher amyloid formation, had lower beta cell apoptosis and higher islet beta cell area than non-treated cultured islets [29]. Thus, GLP-1R agonists may protect islet beta cells from amyloid toxicity even after formation of hIAPP aggregates.

Finally, consistent with recent findings in $\mathrm{h} I A P P$-expressing mice [23], our studies showed that amyloid formation in cultured human islets is associated with increased levels of phospho-JNK in beta cells. We further demonstrated that exenatide-treated islets had markedly lower levels of beta cell phospho-JNK, suggesting that exenatide may protect islet beta cells from amyloid toxicity by reducing JNK activation. Interestingly, elevated JNK phosphorylation and prevention of its activation by exenatide were recently reported in a mouse model of Alzheimer's disease [48], raising the idea that different forms of amyloidogenesis share similar mechanisms of toxicity.
In summary, GLP-1R agonists may provide a feasible approach to enhance beta cell function and preserve beta cell mass during pre-transplant islet culture. Improving the function of beta cells with GLP-1R agonists restores impaired prohIAPP processing and reduces hIAPP aggregation and its beta cell toxicity, in conditions associated with islet amyloid formation such as type 2 diabetes, islet culture and transplantation.

Acknowledgements Human islets for these studies were provided by the Ike Barber Human Islet Transplant Laboratory (Vancouver, BC, Canada). Antisera specific to the $\mathrm{NH}_{2}$ - and $\mathrm{COOH}$-terminal of prohIAPP were a gift from C. B. Verchere (University of British Columbia, Vancouver, BC, Canada). We gratefully acknowledge the outstanding technical assistance of I. Barta (Department of Pathology and Laboratory Medicine, University of British Columbia, Vancouver, Canada), A. Asadi and T. Webber (Department of Cellular and Physiological Sciences, University of British Columbia, Canada) to the completion of these studies.

Funding This work was supported by an operating grant from the Canadian Institutes of Health Research to L. Marzban (MOP-81375). Infrastructure support was provided by grants from the Canadian Foundation for Innovation (L. Marzban) and the Michael Smith Foundation for Health Research (MSFHR) to the Centre for Human Islet Transplantation and Beta-Cell Regeneration (G. L. Warnock). Y. J. Park is supported by a studentship from the CIHR Transplant Research Training Program. L. Marzban is a Scholar of the Canadian Diabetes Association and T. J. Kieffer is an MSFHR Senior Scholar.

Contribution statement All authors contributed to the conception and design or the analysis and interpretation of data, and drafting the article or revising it critically for important intellectual content. All authors gave final approval of the version to be published.

Duality of interest The authors declare that there is no duality of interest associated with this manuscript.

\section{References}

1. Donath MY, Ehses JA, Maedler K et al (2005) Mechanisms of beta-cell death in type 2 diabetes. Diabetes 54(suppl 2):S108-S113

2. Prentki M, Nolan CJ (2006) Islet beta cell failure in type 2 diabetes. J Clin Invest 116:1802-1812

3. Haataja L, Gurlo T, Huang CJ, Butler PC (2008) Islet amyloid in type 2 diabetes and the toxic oligomer hypothesis. Endocr Rev 29:303-316

4. Westermark P, Andersson A, Westermark GT (2011) Islet amyloid polypeptide, islet amyloid, and diabetes mellitus. Physiol Rev 91:795-826

5. Jurgens CA, Toukatly MN, Fligner CL et al (2011) Beta-cell loss and beta-cell apoptosis in human type 2 diabetes are related to islet amyloid deposition. Am J Pathol 178:2632-2640

6. Marzban L, Tomas A, Becker TC et al (2008) Small interfering RNA-mediated suppression of proislet amyloid polypeptide expression inhibits islet amyloid formation and enhances survival of human islets in culture. Diabetes 57:3045-3055 
7. Law E, Lu S, Kieffer TJ et al (2010) Differences between amyloid toxicity in alpha and beta cells in human and mouse islets and the role of caspase-3. Diabetologia 53:1415-1427

8. Park YJ, Lee S, Kieffer TJ et al (2012) Deletion of Fas protects islet beta cells from cytotoxic effects of human islet amyloid polypeptide. Diabetologia 55:1035-1047

9. Westermark G, Westermark P, Eizirik DL et al (1999) Differences in amyloid deposition in islets of transgenic mice expressing human islet amyloid polypeptide versus human islets implanted into nude mice. Metabolism 48:448-454

10. Potter KJ, Abedini A, Marek P et al (2010) Islet amyloid deposition limits the viability of human islet grafts but not porcine islet grafts. Proc Natl Acad Sci USA 107:4305-4310

11. Westermark GT, Westermark P, Berne C, Korsgren O (2008) Widespread amyloid deposition in transplanted human pancreatic islets. N Engl J Med 359:977-979

12. Westermark GT, Davalli AM, Secchi A et al (2012) Further evidence for amyloid deposition in clinical pancreatic islet grafts. Transplantation 93:219-223

13. Udayasankar J, Kodama K, Hull RL et al (2009) Amyloid formation results in recurrence of hyperglycaemia following transplantation of human IAPP transgenic mouse islets. Diabetologia 52:145-153

14. Westwell-Roper C, Dai DL, Soukhatcheva G et al (2011) IL-1 blockade attenuates islet amyloid polypeptide-induced proinflammatory cytokine release and pancreatic islet graft dysfunction. J Immunol 187:2755-2765

15. Engel MF, Khemtemourian L, Kleijer CC et al (2008) Membrane damage by human islet amyloid polypeptide through fibril growth at the membrane. Proc Natl Acad Sci USA 105:6033-6038

16. Last NB, Rhoades E, Miranker AD (2011) Islet amyloid polypeptide demonstrates a persistent capacity to disrupt membrane integrity. Proc Natl Acad Sci USA 108:9460-9465

17. Zhang S, Liu H, Yu H, Cooper GJ (2007) Fas-associated death receptor signaling evoked by human amylin in islet beta-cells. Diabetes 57:348-356

18. Park K, Verchere CB (2001) Identification of a heparin binding domain in the $\mathrm{N}$-terminal cleavage site of pro-islet amyloid polypeptide. Implications for islet amyloid formation. J Biol Chem 276:16611-16616

19. Casas S, Novials A, Reimann F, Gomis R, Gribble FM (2008) Calcium elevation in mouse pancreatic beta cells evoked by extracellular human islet amyloid polypeptide involves activation of the mechanosensitive ion channel TRPV4. Diabetologia 51:2252-2262

20. Huang CJ, Lin CY, Haataja L et al (2007) High expression rates of human islet amyloid polypeptide induce endoplasmic reticulum stress mediated beta-cell apoptosis, a characteristic of humans with type 2 but not type 1 diabetes. Diabetes 56:2016-2027

21. Costes S, Huang CJ, Gurlo T et al (2011) Beta-cell dysfunctional ERAD/ubiquitin/proteasome system in type 2 diabetes mediated by islet amyloid polypeptide-induced UCH-L1 deficiency. Diabetes 60:227-238

22. Zraika S, Hull RL, Udayasankar J et al (2009) Oxidative stress is induced by islet amyloid formation and time-dependently mediates amyloid-induced beta cell apoptosis. Diabetologia 52:626-635

23. Subramanian SL, Hull RL, Zraika S, Aston-Mourney K, Udayasankar J, Kahn SE (2012) cJUN N-terminal kinase (JNK) activation mediates islet amyloid-induced beta cell apoptosis in cultured human islet amyloid polypeptide transgenic mouse islets. Diabetologia 55:166-174

24. Rivera JF, Gurlo T, Daval M et al (2011) Human-IAPP disrupts the autophagy/lysosomal pathway in pancreatic beta-cells: protective role of p62-positive cytoplasmic inclusions. Cell Death Differ $18: 415-426$

25. Kahn SE, D'Alessio DA, Schwartz MW et al (1990) Evidence of cosecretion of islet amyloid polypeptide and insulin by beta-cells. Diabetes 39:634-638
26. Westermark P, Engstrom U, Johnson KH, Westermark GT, Betsholtz C (1990) Islet amyloid polypeptide: pinpointing amino acid residues linked to amyloid fibril formation. Proc Natl Acad Sci USA 87:5036-5040

27. Hou X, Ling Z, Quartier E et al (1999) Prolonged exposure of pancreatic beta cells to raised glucose concentrations results in increased cellular content of islet amyloid polypeptide precursors. Diabetologia 42:188-194

28. Marzban L, Trigo-Gonzalez G, Verchere CB (2005) Processing of pro-islet amyloid polypeptide in the constitutive and regulated secretory pathways of beta cells. Mol Endocrinol 19:2154 2163

29. Aston-Mourney K, Hull RL, Zraika S, Udayasankar J, Subramanian SL, Kahn SE (2011) Exendin-4 increases islet amyloid deposition but offsets the resultant beta cell toxicity in human islet amyloid polypeptide transgenic mouse islets. Diabetologia 54:1756-1765

30. Paulsson JF, Westermark GT (2005) Aberrant processing of human proislet amyloid polypeptide results in increased amyloid formation. Diabetes 54:2117-2125

31. Marzban L, Rhodes CJ, Steiner DF, Haataja L, Halban PA, Verchere $\mathrm{CB}$ (2006) Impaired $\mathrm{NH}_{2}$-terminal processing of human proislet amyloid polypeptide by the prohormone convertase PC2 leads to amyloid formation and cell death. Diabetes 55:2192-2201

32. Wang J, Xu J, Finnerty J, Furuta M, Steiner DF, Verchere CB (2001) The prohormone convertase enzyme 2 (PC2) is essential for processing pro-islet amyloid polypeptide at the $\mathrm{NH}_{2}$-terminal cleavage site. Diabetes 50:534-539

33. Marzban L, Trigo-Gonzalez G, Zhu X et al (2004) Role of beta-cell prohormone convertase (PC) $1 / 3$ in processing of pro-islet amyloid polypeptide. Diabetes 53:141-148

34. Farilla L, Bulotta A, Hirshberg B et al (2003) Glucagon-like peptide 1 inhibits cell apoptosis and improves glucose responsiveness of freshly isolated human islets. Endocrinology 144:51495158

35. Li L, El-Kholy W, Rhodes CJ, Brubaker PL (2005) Glucagonlike peptide-1 protects beta cells from cytokine-induced apoptosis and necrosis: role of protein kinase B. Diabetologia 48:13391349

36. Cunha DA, Ladriere L, Ortis F et al (2009) Glucagon-like peptide1 agonists protect pancreatic beta-cells from lipotoxic endoplasmic reticulum stress through upregulation of BiP and JunB. Diabetes 58:2851-2862

37. Johnson JD, Ao Z, Ao P et al (2009) Different effects of FK506, rapamycin, and mycophenolate mofetil on glucose-stimulated insulin release and apoptosis in human islets. Cell Transplant $18: 833-845$

38. Fan R, Li X, Gu X, Chan JC, Xu G (2010) Exendin-4 protects pancreatic beta cells from human islet amyloid polypeptideinduced cell damage: potential involvement of AKT and mitochondria biogenesis. Diabetes Obes Metab 12:815-824

39. Riedel MJ, Gaddy DF, Asadi A, Robbins PD, Kieffer TJ (2010) DsAAV8-mediated expression of glucagon-like peptide-1 in pancreatic beta-cells ameliorates streptozotocin-induced diabetes. Gene Ther 17:171-180

40. Hansen KB, Knop FK, Holst JJ, Vilsboll T (2009) Treatment of type 2 diabetes with glucagon-like peptide-1 receptor agonists. Int J Clin Pract 63:1154-1160

41. Garber AJ (2010) Incretin-based therapies in the management of type 2 diabetes: rationale and reality in a managed care setting. Am J Manag Care 16:S187-S194

42. Ghofaili KA, Fung M, Ao Z et al (2007) Effect of exenatide on beta cell function after islet transplantation in type 1 diabetes. Transplantation 83:24-28

43. Faradji RN, Froud T, Messinger S et al (2009) Long-term metabolic and hormonal effects of exenatide on islet transplant recipients with allograft dysfunction. Cell Transplant 18:1247-1259 
44. Wang Q, Li L, Xu E, Wong V, Rhodes C, Brubaker PL (2004) Glucagon-like peptide-1 regulates proliferation and apoptosis via activation of protein kinase B in pancreatic INS-1 beta cells. Diabetologia 47:478-487

45. Xu G, Kaneto H, Laybutt DR et al (2007) Downregulation of GLP-1 and GIP receptor expression by hyperglycemia: possible contribution to impaired incretin effects in diabetes. Diabetes 56:1551-1558

46. Verchere CB, D'Alessio DA, Wang S, Andrikopoulos S, Kahn SE (1997) Transgenic overproduction of islet amyloid polypeptide (amylin) is not sufficient for islet amyloid formation. Horm Metab Res 29:311-316

47. McClean PL, Parthsarathy V, Faivre E, Holscher C (2011) The diabetes drug liraglutide prevents degenerative processes in a mouse model of Alzheimer's disease. J Neurosci 31:6587-6594

48. Bomfim TR, Forny-Germano L, Sathler LB et al (2012) An antidiabetes agent protects the mouse brain from defective insulin signaling caused by Alzheimer's disease-associated A $\beta$ oligomers. J Clin Invest 122:1339-1353 